percentage uptake criterion is to be used a more realistic figure for a significant difference would be $8 \%$ rather than $15 \%$ with the usual collimator employed. However, despite the larger number of positive indications obtained with the statistical index than with the percentage uptake index, both these indices fail to take account of the unequal distribution of fibrinogen in the blood and tissue of the limbs at adjacent points.

The use of the relative uptake index, on the other hand, avoids the necessity of having to assess the significance of counts at any one point on a leg by reference to those made at another. It is interesting that it gave not only a number of positive results in addition to those given by the percentage uptake index but also a number of negative results where the latter was positive. This was not entirely unexpected, since anatomical variations in legs are such that when only one value $(15 \%)$ is used for significance the percentage uptake index is most unlikely to give correct results for all points on all patients.

Phlebographic confirmation of our results was not carried out since, as noted above, the standardization of a technique by one which is less sensitive is regarded as unhelpful.

The use of the relative uptake index avoids the application of the same arbitrary limits for a positive diagnosis to all patients. The reported incidence of venous thrombosis detected by ${ }^{1: 2}$ I-fibrinogen is of the order of $30 \%$ (Flan= et al., 1968; Negus et al., 1968; Hills el al., 1972). On the basis of the results reported here this seems to us to be a low estimate. We have shown that the sensitivity of the method is increased when account is taken of variations in count rates and anatomy, so that the relative uptake index may well provide a more accurate indicator of the presence of deep vein thrombosis than those in current use. Caution must be advised, $\infty$ however, in estimating the incidence of thrombosis from the data reported here, because the patients studied were selected specially to give a high number of positive results.

The method of counting does not differ from that commonly used, and the mathematical analysis is simple and $\stackrel{\vec{\rho}}{\rightarrow}$ suitable for routine use. By using the program daily results can $\overline{0}$ be obtained a few minutes after the data have been fed $\underline{\bar{O}}$ into the computer. The computer program will also draw $\frac{\bar{s}}{\frac{1}{T}}$ attention to anatomical points at which a significant change $\stackrel{\mathbb{\Omega}}{\Omega}$ has occurred; this form of data processing saves a great deal of time both in the calculation and in the interpretation of the results.

\section{References}

Atkins, P., and Hawkins, L. A. (1965). Lancet, 2, 1217.

Atkins, P., and Hawkins, L. A. (1968). British fournal of Surgery, 55, 825. Browse, N. L., et al. (1971). British Medical fournal, 4, 325.

Flanc, C., Kakkar, V. V., and Clarke, M. B. (1968). British fournal of î

Surgery, 55, 742.
Hills, N. H., Pflug, J. J., Jeyasingh, K., Boardman, L., and Calnan, J. S. (1972). British Medical fournal, 1, 131 .

Negus, D., Pinto, D. J., Le Quesne, L. P., Brown, N., and Chapman, M. N (1968). British Fournal of Surgery, 55, 835.

Pai, B. Y., and Negus, D. (1971). Lancet, 2, 1098. (1964). Canadian fournal of Surgery, 7, 215.

\title{
Assessment of Upper Airways Obstruction
}

\author{
D. W. EMPEY
}

British Medical fournal, 1972, 3, 503-505

\begin{abstract}
Summary
An indication of obstruction to the upper airways (trachea and larynx) may be obtained by calculating the ratio of the forced expired volume in one second to the peak expiratory flow rate $\left(F E V_{1} /\right.$ PEFR). This index was found to be usually less than 10 in normal subjects (mean 7.3), and in patients with asthma (mean 6.9), chronic bronchitis (mean 7.7), or interstitial lung disease (mean 6.3). A study of simulated upper airways obstruction showed that this index rises as the obstruction becones more severe. All of 18 patients with proved upper airways obstruction had $\mathrm{FEV}_{1} /$ PEFR indices greater than 10 (mean 14.0). This test can be carried out with forced expiratory manoeuvres only, and it does not require the use of complicated equipment. An FEV $/$ PEFR ratio greater than 10, when upper airways obstruction is suspected, indicates that significant obstruction may be present. High values suggest that the obstruction may be severe, and that further investigations are indicated.
\end{abstract}

Department of Chest Medicine, London Hospital, London E.1 D. W. EMPEY, M.B., M.R.C.P., Wellcome Research Fellow

\section{Introduction}

Lesions of the upper airways, such as tracheal stenosis or laryngeal tumours, are relatively uncommon compared with obstruction of the lower airways, such as occurs in asthma and chronic bronchitis. It is, however, important to recognize upper airways obstruction, especially as the patients may go into respiratory failure (Bland et al., 1969; Clark, 1970; Hughes et al., 1972). Frequently neither the nature nor the severity of the $\tilde{\sigma}$ lesion is realized clinically unless endoscopy is performed. I Conventional lung function tests may not fully disclose the extent of the obstruction, and for this reason more complex $N$ tests have been devised to differentiate between upper and lower airways obstruction. The most satisfactory of these involves the construction of flow-volume curves (Jordanoglou and Pride, 1968). Expensive equipment is required for this, however, and the results depend to some extent on the cooperation and effort of the patient.

Attempts have previously been made to obtain by indirect means some of the information given by flow-volume curves, but these methods suffer from disadvantages similar to those involved in constructing actual flow-volume curves (Nairn and McNeill, 1963; Clark, 1970). Theoretical considerations (see below) suggest that it might be possible to identify patients with upper airways obstruction on the basis of forced expiratory flow tests using readily available equipment-namely, a dry spirometer and a Wright peak flow meter. The present study was designed to test this hypothesis by comparing the results obtained from subjects with real and simulated upper airways obstruction with those from normal subjects and patients with lower airways obstruction or interstitial lung disease. 


\section{Theoretical Considerations}

Study of maximal inspiratory flow-volume curves shows that increased resistance in the upper airways leads to a reduction of inspiratory flow rates at all lung volumes but that the contour of the curve still resembles the normal (Fig. 1 a). Excessive inspiratory dynamic compression of the extrathoracic airways may occur because the intratracheal pressure below the stenosis is much lower than atmospheric pressure. The result is to make the inspiratory resistance greater than the expiratory resistance when upper airways obstruction is present. The peak inspiratory flow rate (PIFR) and the forced inspired volume in one second $\left(\right.$ FIV $\left._{1}\right)$ are therefore reduced to a greater extent than the peak expiratory flow rate (PEFR) and the forced expired volume in one second $\left(\mathrm{FEV}_{1}\right)$ in the presence of extrathoracic airways obstruction. This has been the basis of some previously described tests for upper airways obstruction. Nairn and McNeill (1963) found that PEFR/PIFR ratio to be increased in one case of laryngeal obstruction. They used an adapted peak flow meter to measure the PIFR, but this is not commercially available. Clark (1970) found the $\mathrm{FEV}_{1} / \mathrm{FIV}_{1}$ ratio to be increased in four patients with upper airways obstruction. For both these tests the patient must be trained to perform an inspiratory manoeuvre with maximal effort.

The expiratory loop of the flow-volume curve shows that in normal subjects the expiratory flow rate is highest soon after expiration has begun and decreases as the residual volume is approached (Fig. 1). When upper airways obstruction is present a large reduction of flow occurs at high lung volumes only, so that the total volume exhaled in one second $\left(F E V_{1}\right)$ is almost normal. This change can be explained by the difference in factors influencing flow at high and low lung volumes. Near

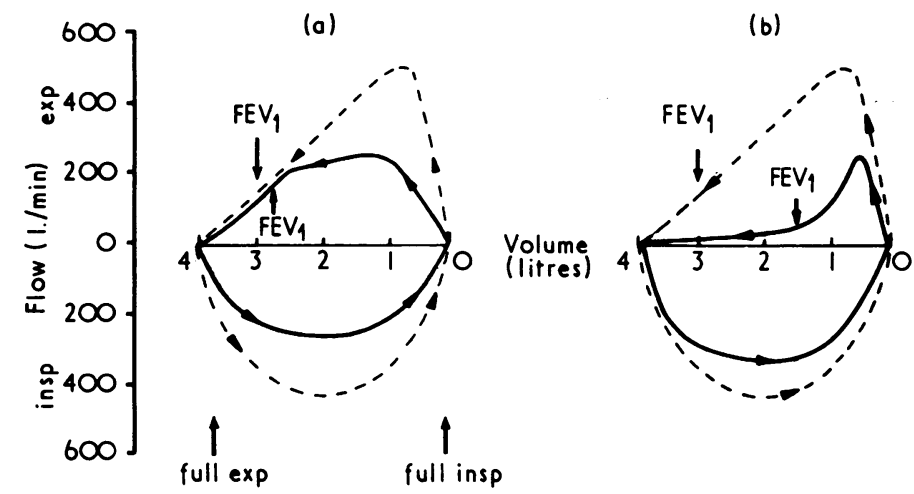

FIG. 1-Maximal expiratory and inspiratory flow-volume curves (continuous lines) for (a) a patient with upper airways obstruction, and (b) a patient with asthma. The interrupted lines show the flow-volume curve for a normal subject. (After Pride, 1971). to total lung capacity flow is effort-dependent and is influenced by alveolar pressure (elastic recoil pressure plus pleural pressure) and the resistance of the whole respiratory tract. Increased resistance in the upper respiratory tract would therefore decrease maximal flow rates at high lung volumes. At lower lung volumes, however, expiratory dynamic compression of the intrathoracic airways occurs. Flow then depends on the elastic recoil pressure (without pleural pressure) and the resistance of the smaller intrathoracic airways distal to the point where compression has occurred. Thus effort and upper airways resistance are not factors in limiting flow at low lung volumes (Hyatt et al., 1958; Mead et al., 1967; Pride et al., 1967).

The $\mathrm{FEV}_{1}$ measurement is obtained from the changes in maximal flow over a whole range of lung volumes and is hence much less dependent on effort and upper airways resistance than the PEFR. When upper airways obstruction is present the reduction in PEFR will be greater than the reduction in FEV . This contrasts with lower airways obstruction-for example, asthma (Fig. 1 b) -in which the reductions in FEV ${ }_{1}$ and PEFR are roughly proportional to each other. These changes are shown by the observations of Miller and Hyatt (1969), who studied simulated upper airways obstruction, and of Harrison and Swarbrick (1971), who studied patients with asthma. An increase in the index FEV $_{1} /$ PEFR whould therefore be expected when upper airways obstruction is present.

\section{Methods}

Ten normal subjects, 18 patients with upper airways obstruction, 26 patients with asthma or chronic bronchitis, and 11 patients with restrictive lung disease were studied. Upper airways obstruction was simulated in the normal subjects by the use of mouthpieces fitted with orifices $10,8,6$, and $4 \mathrm{~mm}$ in diameter. This is similar to the technique of Miller and Hyatt (1969). In all the patients with upper airways obstruction the diagnosis had been made by direct or indirect endoscopy. Clinical details of these patients are given in the Table. The patients with lower airways obstruction had $\mathrm{FEV}_{1}$ and PEFR values ranging from 15 to $70 \%$ of predicted normal, and a total of $\mathbf{4 0}$ observations were made on these patients. All the patients with restrictive lung disease had a forced vital capacity (FVC) below $70 \%$ of predicted normal and an $\mathrm{FEV}_{1} / \mathrm{FVC}$ ratio greater than $70 \%$. Twenty observations were made on this group of patients.

A standard forced expiratory manoeuvre was performed to obtain the $\mathrm{FEV}_{1}$, using a Vitalograph spirometer (Drew and Hughes, 1969). The best of three recordings was taken and expressed in millilitres at body temperature, pressure, and saturation (B.T.P.S.). A Wright peak flow meter was used to measure the PEFR in litres per minute, and again the best of three attempts was accepted. The ratio $\mathrm{FEV}_{1} / \mathrm{PEFR}$ was calculated in each case.

Clinical Details of 18 Patients with Upper Airways Obstruction

\begin{tabular}{|c|c|c|c|c|c|c|c|c|c|}
\hline \multirow{2}{*}{\multicolumn{2}{|c|}{ Case No. }} & \multirow{2}{*}{ Sex } & \multirow{2}{*}{ Age } & \multirow{2}{*}{ Diagnosis } & \multirow{2}{*}{ Stridor } & \multirow{2}{*}{ Dyspnoea } & \multirow{2}{*}{ Other Details } & \multicolumn{2}{|c|}{ FEVI/PEFR } \\
\hline & & & & & & & & $\mathrm{ml} / 1$. per $\min$ & Ratio \\
\hline 1 & .. & F. & 46 & Subglottic stenosis & Present & Present & Tracheostomy needed, mixed & $1,285 / 60$ & $21 \cdot 4$ \\
\hline $\begin{array}{r}2 \\
3 \\
4 \\
5 \\
6 \\
7 \\
8 \\
9 \\
10 \\
11 \\
12 \\
13 \\
14 \\
15 \\
16 \\
17 \\
18\end{array}$ & $\begin{array}{l}\because \\
\because \\
\because \\
\because \\
\because \\
\because \\
\because \\
\because \\
\because \\
\because \\
\because\end{array}$ & $\begin{array}{l}\text { F. } \\
\text { M. } \\
\text { F. } \\
\text { F. } \\
\text { M. } \\
\text { M. } \\
\text { F. } \\
\text { M. } \\
\text { F. } \\
\text { F. } \\
\text { M. } \\
\text { F. } \\
\text { F. } \\
\text { F. }\end{array}$ & $\begin{array}{l}77 \\
62 \\
23 \\
54 \\
69 \\
35 \\
17 \\
49 \\
74 \\
40 \\
70 \\
72 \\
63 \\
58 \\
56 \\
37 \\
68\end{array}$ & $\begin{array}{l}\text { Recurrent carcinoma trachea } \\
\text { Carcinoma pharynx } \\
\text { Bilateral vocal cord palsy } \\
\text { Bilateral vocal cord palsy } \\
\text { Bilateral vocal cord palsy } \\
\text { Bilateral vocal cord palsy } \\
\text { Tracheal stenosis } \\
\text { Bilateral vocal cord palsy } \\
\text { Bilateral vocal cord palsy } \\
\text { Tracheal stenosis } \\
\text { Bilateral vocal cord palsy } \\
\text { Bilateral vocal cord palsy } \\
\text { Carcinoma larynx } \\
\text { Pharyngeal carcinoma } \\
\text { Carcinoma larynx } \\
\text { Bilateral vocal cord palsy } \\
\text { Carcinoma thyroid (compressing trachea) }\end{array}$ & $\begin{array}{l}\text { Present } \\
\text { Present } \\
\text { Present } \\
\text { Present } \\
\text { Present } \\
\text { Present } \\
\text { Absent } \\
\text { Present } \\
\text { Absent } \\
\text { Present } \\
\text { Present } \\
\text { Present } \\
\text { Present } \\
\text { Present } \\
\text { Present } \\
\text { Present } \\
\text { Present }\end{array}$ & $\begin{array}{l}\text { Present } \\
\text { Present } \\
\text { Absent } \\
\text { Absent } \\
\text { Present } \\
\text { Absent } \\
\text { Absent } \\
\text { Absent } \\
\text { Absent } \\
\text { Absent } \\
\text { Absent } \\
\text { Absent } \\
\text { Absent } \\
\text { Absent } \\
\text { Absent } \\
\text { Absent } \\
\text { Present }\end{array}$ & $\begin{array}{l}\text { Dilatation of trachea required } \\
\text { Tracheostomy needed } \\
\text { Arytenoidectomy performed } \\
\text { Arytenoidectomy performed } \\
\text { Tracheostomy needed }\end{array}$ & $\begin{array}{l}755 / 40 \\
2,800 / 150 \\
2,450 / 165 \\
1,450 / 100 \\
1,500 / 110 \\
2,550 / 185 \\
2,750 / 200 \\
1,975 / 150 \\
2,160 / 160 \\
3,800 / 300 \\
1,580 / 130 \\
1,200 / 100 \\
2,380 / 210 \\
2,075 / 180 \\
2,700 / 250 \\
2,960 / 290 \\
885 / 65 \\
1,940 / 240\end{array}$ & $\begin{array}{l}18.9 \\
18.7 \\
14.9 \\
14.5 \\
13.6 \\
13.8 \\
13.8 \\
13.2 \\
13.5 \\
12.7 \\
12.2 \\
12.0 \\
11.3 \\
11.5 \\
10.8 \\
10.2 \\
13.6 \\
8.1\end{array}$ \\
\hline
\end{tabular}




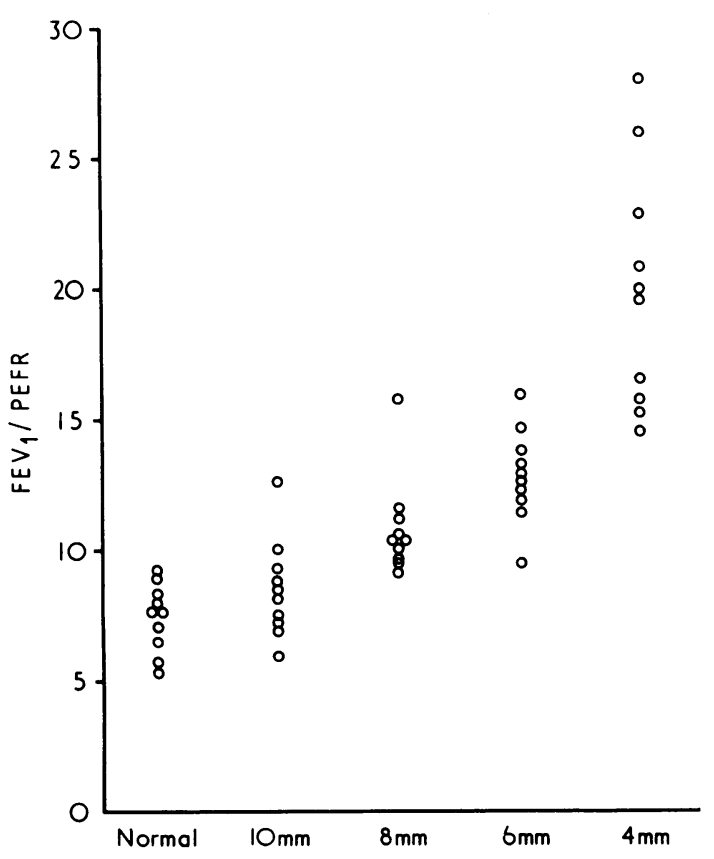

FIG. 2-FEV $/$ PEFR ratio in normal subjects with and without resistances added at mouthpiece. Diameter of orifice is shown in each case.

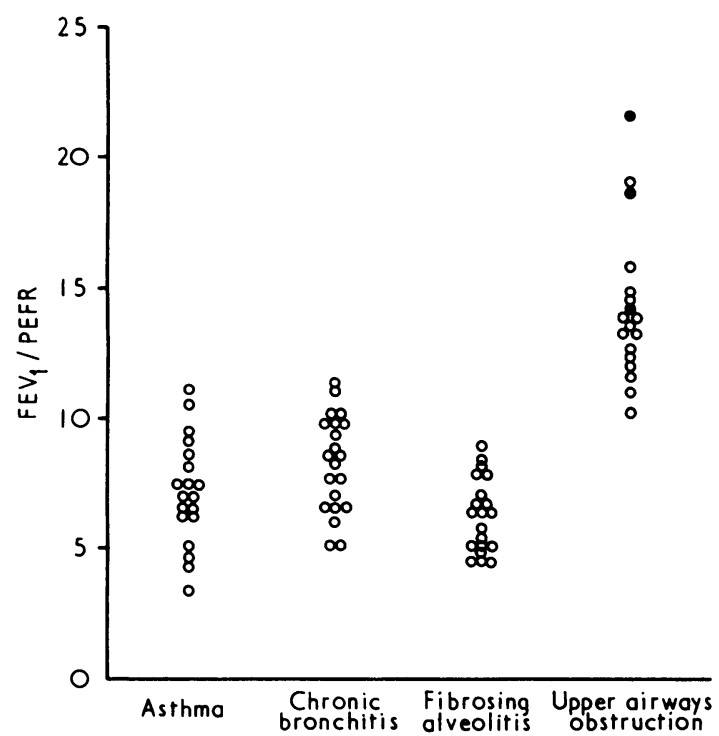

FIG. 3- $\mathrm{FEV}_{1} / \mathrm{PEFR}$ ratio in patients with lower airways obstruction, interstitial lung disease, and upper airways obstruction. Black circles indicate cases requiring tracheostomy.

\section{Results}

The results are given in the Table and in Figs. 2 and 3. In the normal subjects the value of $\mathrm{FEV}_{1} / \mathrm{PEFR}$ was between 5.0 and 10.0 (mean 7.3, S.E. of mean \pm 0.41 ). When small orifices were inserted in the mouthpieces of normal subjects the ratio increased, and once the orifice was $6 \mathrm{~mm}$ or less in diameter most subjects had an index above 10 .

All the patients with upper airways obstruction also had indices above 10 (mean 14.0 , S.E. of mean \pm 0.63 ). The three patients in this group who had obstruction severe enough to warrant tracheostomy had indices greater than 14.0, and the patient with the highest index was in respiratory failure (mixed venous $\mathrm{PCO}_{2} 62 \mathrm{~mm} \mathrm{Hg}$ ). One patient (Case 18) was studied before and after relief of the obstruction. Her index was 13.6 before operation and became normal $(8 \cdot 1)$ when the thyroid carcinoma which had been compressing her trachea was removed.

The 37 patients with lower airways obstruction or restrictive lung disease had indices of less than 10 in all but six instances (asthma, mean 6.9, S.E. of mean \pm 0.53 ; chronic bronchitis, mean $7 \cdot 1$, S.E. of mean \pm 0.39 ; fibrosing alveolitis, mean $6 \cdot 3$, S.E. of mean $\pm 0 \cdot 25$ ). There were highly significant differences between the indices of patients with upper airways obstruction and those of each of the other groups of patients and of the normal subjects ( $P<0.01$ in each case). There were no significant differences between the indices of the latter groups of patients and those of normal subjects $(P>0 \cdot 1)$.

\section{Discussion}

There is probably no completely satisfactory indirect method of assessing upper airways obstruction. Flow-volume curves can be helpful but they are not easy to construct and their interpretation is not always clear. The present study suggests that the ratio $\mathrm{FEV}_{1} /$ PEFR can be useful in assessing upper airways obstruction. This index is based on the alteration in the flow-volume curve which occurs when upper airways obstruction is present. The study of normal subjects with simulated upper airways obstruction showed that the index rises as the obstruction becomes more severe. When the index is greater than 10 it is likely that upper airways obstruction is present, higher values being associated with more severe degrees of obstruction. This was also shown by studies on the group of patients whose upper airways obstruction had been proved by endoscopy. Although some patients with severe lower airways obstruction can have $\mathrm{FEV}_{1} / \mathrm{PEFR}$ values slightly greater than 10 (see Fig. 3 ) this does not lead to confusion in practice, as the nature of the airways obstruction is usually clear in these patients. If the results are equivocal further investigation, including endoscopy, may be indicated.

The advantage of this procedure over other methods of assessing upper airways obstruction is the ease with which the expiratory manoeuvres required to measure $\mathrm{FEV}_{1}$ and PEFR can be performed. In addition, the equipment required is standard in most hospitals.

I am grateful to Dr. David Hughes for his advice on the preparation of this paper, to the physicians and surgeons of the London Hospital for allowing me to study patients under their care, to Mr. R. S. Dawkins for advice on surgical aspects of this paper, to Dr. Anne Tattersfield for reading the manuscript, and to Miss Peggy Hodder for secretarial help.

\section{References}

Bland, J. W., Edwards, F. K., and Brinsfield, D. (1969). American fournal of Cardiology, 23, 830 .

Clark, T. J. H. (1970). British Medical fournal, 3, 682.

Drew, C. D. M., and Hughes, D. T. D. (1969). Thorax, 24, 703.

Harrison, B. D. W., and Swarbrick, E. T. (1971). Lancet, 2, 492.

Hughes, D. T. D., Ëmpey, D. W., Cameron, J. M., Sims, B. G. and Taylor, T. H. (1972). Medicine, Science and the Law, 12, 139.

Hyatt, R. E. Schilder, D. P., and Fry, D. L. (1958). Fournal of Applied Physiology, 13, 331 .

Jordanoglou, J., and Pride, N. B. (1968). Thorax, 23, 38. ead, S., Turner, J. M., Macklem

Applied Physiology, 22, 95.
Miller, R. D., and Hyatt, R. E. (1969). Mayo Clinic Proceedings, 44, 145.

Miller, R. D., and Hyatt, R. E. (1969). Mayo Clinic Proceedings, 44, 145.

Nairn, J., and McNeill, R. S. (1963). British Medical Fournal, 1, 1321
Pride, N. B. (1971). British Fournal of Diseases of the Chest, 65, 135.

Pride, N. B., Permitt, S., Riley, R. L., and Bromberger-Barnea, B. (1967). fournal of Applied Physiology, 23, 646. 